Laboratorio de Arte,1-1988 http://dx.doi.org/10.12795/LA.1988.i01.10

\title{
TRES NUEVAS OBRAS DE JUAN DE ESPINAL
}

Enrique Valdivieso

En fechas aún no muy lejanas (1) nos lamentábamos de que se hubiese perdido la representación de Venus y Vulcano que a nombre de Espinal aparece citada en el Inventario de las pinturas requisadas por los franceses en el Alcázar de Sevilla en 1810 (2). Señalábamos en aquella ocasión que hubiera sido interesante conocer el elegante tratamiento que Espinal hubiera podido otorgar a un tema mitológico, el único que por otra parte que hasta ahora se registra en su producción.

Por fortuna, no hemos de lamentar la pérdida de la citada obra, puesto que en un reciente examen, efectuado a parte de los fondos del Museo de Bellas Artes de Sevilla, hemos localizado una pintura cuyo tema es Venus y Vulcano y que muestra claramente el estilo de Juan de Espinal (3). Se trata de una bella representación que con toda probabilidad es la citada en el Inventario antes mencionado y que puede pasar a integrarse dentro de la escasa nómina de pinturas mitológicas pertenecientes a la escuela pictórica sevillana.

En la pintura se describe el momento en que Venus se presenta en la fragua de Vulcano y es reconvenida por este a causa de sus amores con Marte. El viejo herrero aparece interrumpiendo por unos instantes sus trabajos de forja junto a un yunque, en el que está realizando varios escudos y armaduras

(1) Valdivieso, E. Historia de la pintura sevillana. Sevilla, 1986, p. 335.

(2) Gómez Imaz, M. Inventario de las pinturas del palacio y salones del Alcázar de Sevilla, pertenecientes a S. M. C. el Sehor D. José Napoleón. Sevilla, 1917, p. 132, n: 130: "Un cuadro de una tercia de ancho y una y media de alto, Venus y Burcano (sic). Figura en la Sala 3, como original de Juan de Espinal.

(3) Parece ser esta pintura la que Hernández Dlaz cataloga a nombre de Juan Rodrlguez "EI Panadero" en su Catálogo del Museo Provincial de Bellas Artes de Sevilla, 1967, p. 84, n.' 263 con el titulo La fragua de Vulcano y con las medidas $1,55 \times 1,05$. Las medidas del bastidor de esta pintura son $1,61 \times 1,11$. 
que se ven esparcidos por el suelo. Junto a él, aparece, vestida con túnica blanca y manto azul, Venus, advirtiéndose que el artista ha obviado describir la habitual desnudez de su cuerpo en este tipo de escenas, habiéndose atrevido tan sólo a descubrir uno de sus pechos y por otra parte a pintarlo de forma somera Esta circunstancia nos mueve a pensar que en el siglo XVIII y en una fecha que puede oscilar en tomo a 1760 , que es cuando creemos que ha sido realizada esta obra, aún subsistía en Sevilla, dentro de los medios artísticos, la precaución por parte de los pintores, que en el siglo XVII existió el cargo de "veedor de pinturas del Santo Oficio", cargo que desempeñaba un pintor elegido por la Inquisición y que vigilaba el contenido formal y argumental de las pinturas realizadas por los artistas sevillanos.

Al fondo de la pintura, la fragua de Vulcano que se describe en los términos de una cueva, se abre en una oquedad en la que se advierten muy abocetados varios de sus ayudantes, ocupados con sus martillos en forjar armas de hierro. Se encuentra esta pintura actualmente en precario estado de conservación, con parte de su capa pictórica desprendida, aspecto que una restauración adecuada podrá remediar con bastante facilidad.

En colecciones particulares de Madrid se conservan dos pinturas de Espinal que hasta ahora se venían considerando como anónimas (4). La primera de ellas es una elegante representación de Santa Agueda captada de tres cuartos en su anatomía. Aparece vestida con elegantes ropajes dieciochescos mostrando la palma que alegoriza su martirio. Este se representa en segundo plano con pequeñas figuras abocetadas advirtiéndose que la Santa está atada a un poste y que dos sayones se dirigen a élla blandiendo enormes cuchillos.

La segunda pintura representa a San Francisco confortado por un ángel, escena en la que el Santo recibe, después de su estigmatización, una ampolla de bálsamo para aliviar el dolor de sus heridas. Este episodio se desarrolla en el monte Alvema y en él aparece el Santo arrodillado con sus manos recogidas sobre el pecho, teniendo en el suelo los atributos de su oración y penitencia, como son una cruz y una calavera. En segundo plano y leyendo sentado, aparece el hermano León que acompañaba a San Francisco en este trance.

(4) Fueron mencionadas en Valdivieso, E. Historia de la pintura sevillana, Sevilla 1986, p. 335, pero no reproducidas. 


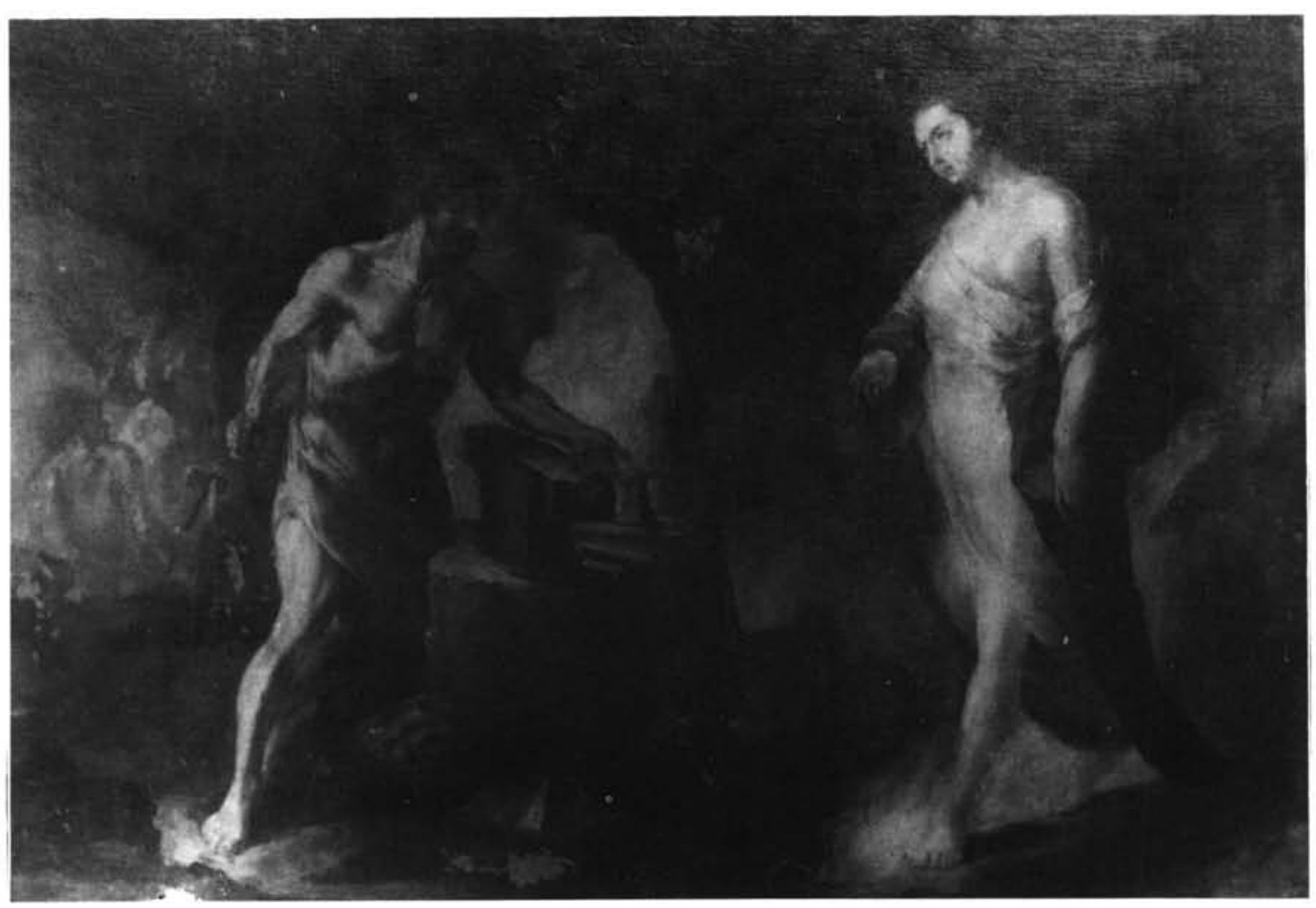

Joan de Espinal. Venus y Vulcano. Sevilla. Museo de Bellas Artes. 


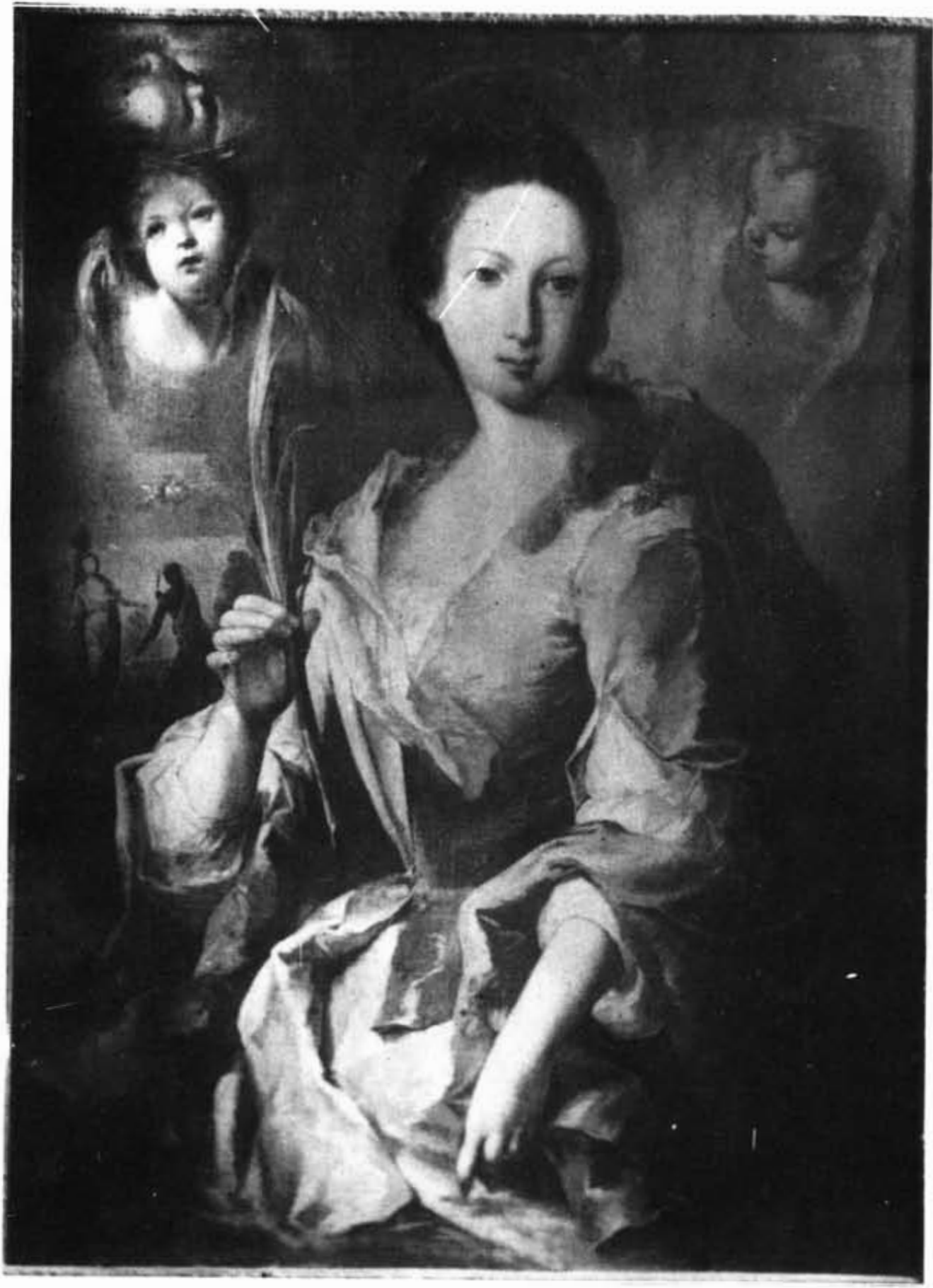

Joan de Espinal. Santa Bárbara. Madrid. Colec. particular. 


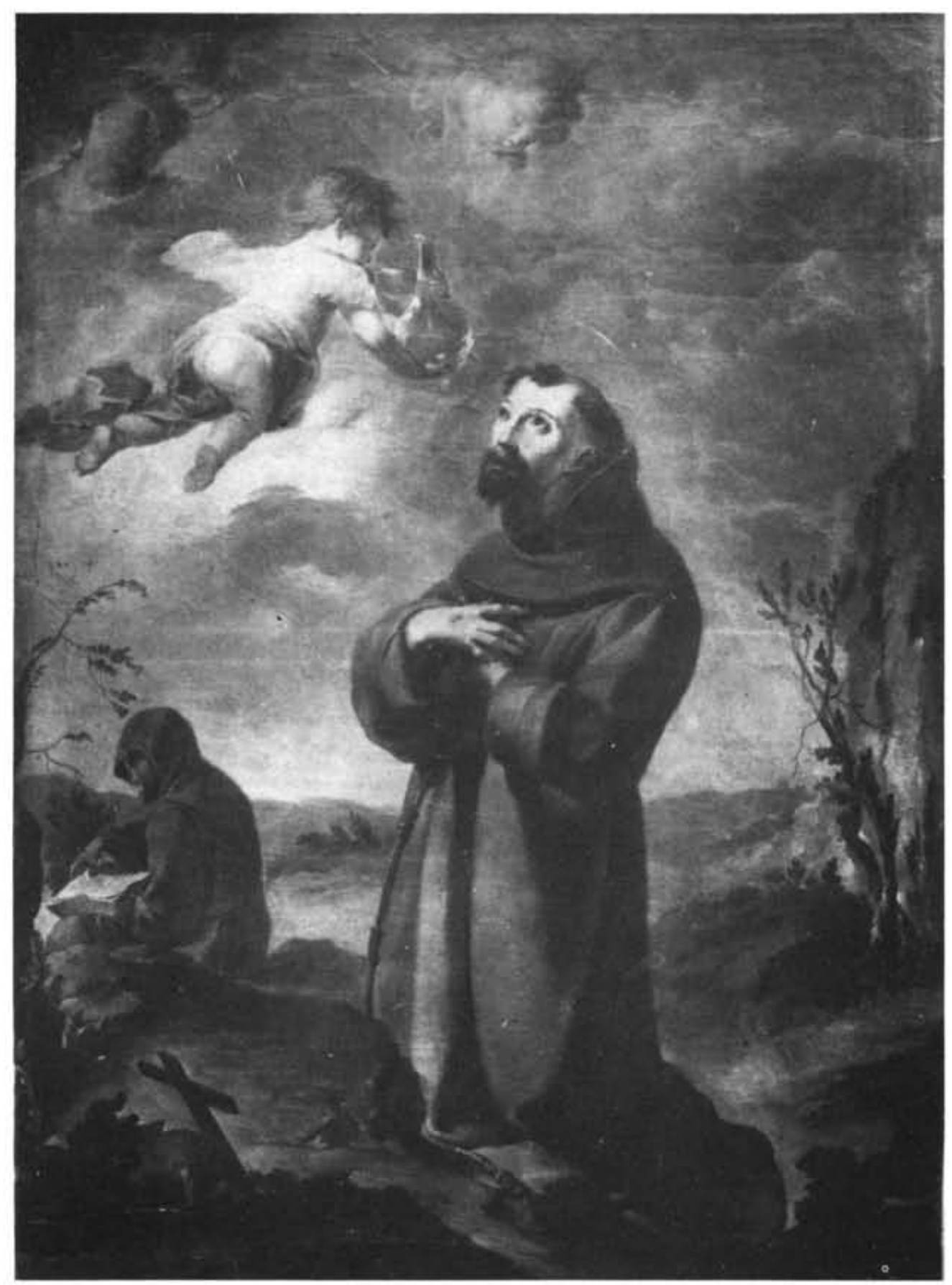

Joan de Espinal. San Francisco recibiendo la ampolla. Madrid. Colec. particular. 